\title{
КРАШЕНИЕ ПРИРОДНЫХ ВОЛОКОН КРАСИТЕЛЯМИ РАСТИТЕЛЬНОГО ПРОИСХОЖДЕНИЯ
}

\section{Ерниязова Анастасия Михайловна}

студент

Научный руководитель: Курагина Надежда Сергеевна

стар. преп. каф. биологии

ФГАОУ ВО «Волгоградский государственный университет»

Аннотация: в странах Скандинавии, Финляндии и США достаточно популярным является крашение, как отдельными частями растений, так и грибами, что нельзя сказать о России, где окрашивание с помощью природных красителей популярно только на территории Югры. В данной статье мы решили опубликовать подробное описание техники крашения природных волокон и наших экспериментов с видами растений и грибов, распространённых на территории Волгоградской области.

Ключевые слова: грибы, растения, окрашивание, природные красители, Мириам Райс.

\section{DYEING OF NATURAL FIBERS WITH DYES OF PLANT ORIGIN}

Ernyazova Anastasia Mikhailovna Scientific adviser: Kuragina Nadezhda Sergeevna

\begin{abstract}
Scandinavia, Finland and the United States, dyeing is quite popular both with individual parts of plants and with fungi, which cannot be said about Russia, where coloring with natural dyes is popular only in the territory of Ugra. In this article, we decided to publish a detailed description of the technique of dyeing natural fibers and our experiments with plant and fungal species common in the Volgograd region.
\end{abstract}

Key words: mushrooms, plants, coloring, natural colorants, Miriam C. Rice

Натуральное окрашивание является не только экологически безопасным на всех его этапах, начиная от самого красителя до утилизации, но также является экономически выгодным, т.к. красители «растут под ногами».

В связи с этим, целью нашего исследования стало выявление видового состава региональной флоры и микобиоты, способного к окрашиванию. 
Цель исследования: изучить и составить свою технологию колорирования шерсти красителями, которые будут получены из растений и макромицетов произрастающих на территории Волгоградской области.

Объектом исследования: красители растительного происхождения, полученные из природных материалов.

\section{История изучения красильных свойств грибов:}

На сегодняшний день продукция из природных материалов постепенно возвращается в нашу культуру. Красильное искусство считается одним из древнейших, но умение красить ткань всегда зависело от развития цивилизации, природных условий, в которых проживал ремесленник, занимавшийся этим делом. До появления искусственных красителей натуральное окрашивание было единственным и незаменимым способом окрашивания текстильных материалов [6,10].

Экопринт стал популярен и экологически безопасным способом окрашивания ткани. Для него используют плоды, цветы, кору, а также растения целиком. Однако сложно представить, что в декорировании тканей и шерсти можно использовать грибы, поэтому нужно обратить на них большое внимание [6].

Окрашивание, производимое макромицетами довольно сложное и специфическое ремесло, материал необходимый для него найти можно не везде и довольно трудно. Но, не смотря на всё, это занятие является достаточно популярным. Выпущено немало фундаментальных книг по грибокрашению, создают международные форумы, где собираются сотни участников.

Основоположником грибного окрашивания принято считать жительницу США Мириам Райс (рис. 1). Заняться данным делом она решила, работая художником, в 1960 году она занималась с детьми в Центре искусств, который располагался в Калифорнии. Параллельно своей работе она находилась в поисках натуральных красителей, которые можно было использовать для гравюры на дереве (ксилография). Как-то раз миколог Гарри Тьер предложил ей вместе с ним сходить по грибы, их целью было узнать больше о местных видах. После сбора некоторых видов грибов она ради эксперимента добавила в свою красильную ёмкость к шерстяной пряже кусочки серно-жёлтого ложноопёнка Naematoloma fasciculare Huds. - и в итоге у неё получился ярко-лимонный цвет. С этого момента она стала углублять свои знания о природных красителях, а именно о грибах [5]. 
Мириам постоянно посещала различные ярмарки и базары, а также леса и поля, пытаясь найти интересные и подходящие виды для крашения. 1972 год в Калифорнии считали урожайным, собрав необходимые виды грибов, у неё сформировалась своя красильная коллекция.

В 1974 году совместно с иллюстратором Дороти Биби издала книгу «Let's Try Mushrooms for Color». За ней в 1980-м последовала книга «Mushrooms for Color», дополненная её собственными микробиологическими исследованиями, а также химическими опытами Эрика Сандстрёма о красящих пигментах грибов. Крашение грибами стало настолько популярным, что в 1985 году в Швеции даже образовалось некоммерческое общество ТНЕ INTERNATIONAL MUSHROOM DYE INSTITUTE - Международный институт грибного крашения. Позже Мириам увлеклась экопроектами и разлагаемыми материалами, придумала бумагу из грибов и грибные акварельные краски - со своими разработками она участвовала в «грибном симпозиуме» 1999 года в Норвегии. Последней ее книгой стала «Mushrooms for Dyes, Paper, Pigments \& Myco-Stix».

Благодаря работам и исследованиям Мириам Райс идея о крашения грибами разошлась практически по всем странам. Каждый регион имеет свою необыкновенную и незаменимую палитру оттенков. И как нам, кажется, нужно продолжать то дело, что в своё время открыла Мириам.

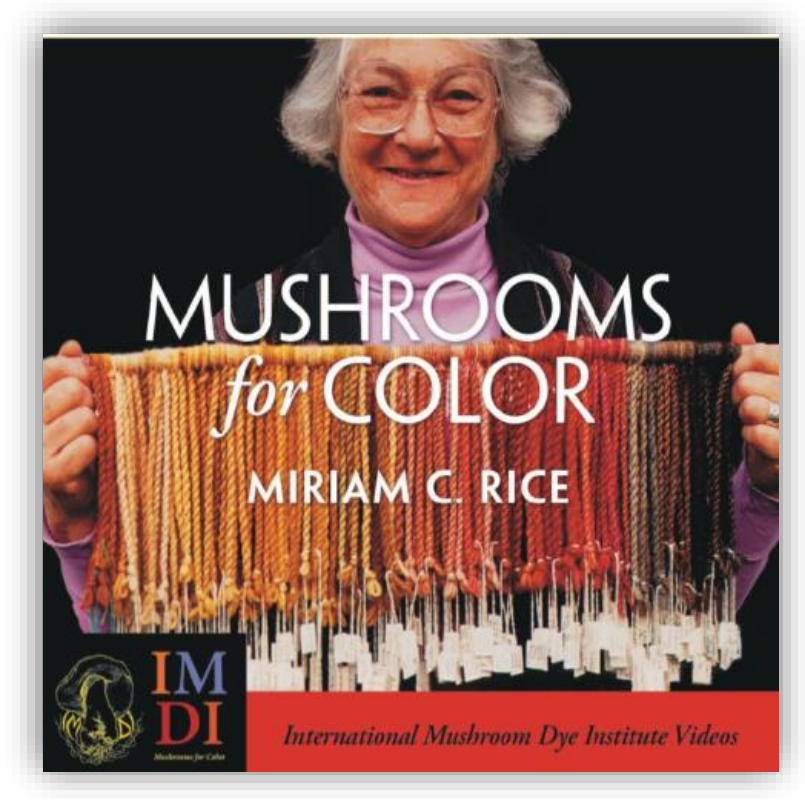

Рис. 1. Мириам Райс с частью своей коллекцией 


\section{Географическое положение и границы района исследования:}

Волгоградская область расположена на юго-востоке Европейской части России, в районе Нижнего Поволжья и среднего течения Дона (рис. 2). С севера на юг и запада на восток её территория тянется более чем на 400 км.

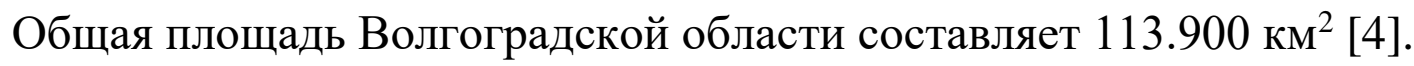

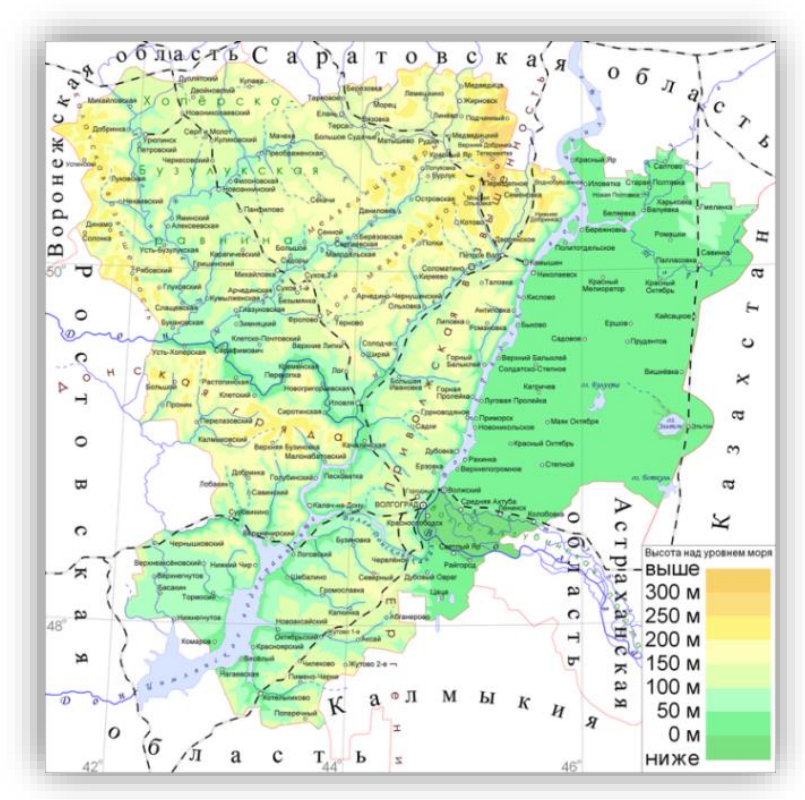

\section{Рис. 2. Физическая карта Волгоградской области}

\section{Материалы и методы исследования:}

В работе были использованы стандартные методы исследования, а именно:

- маршрутный метод (каждый маршрут составлял около 10 км);

- микроскопический метод анализа (световая микроскопия). Образцы определялись с помощью работ российских микологов [2-4];

- фотографический метод (фотоаппарат Nikon D750 kit);

- метод окрашивания с помощью реактивов: алюмокалиевые квасцы $\mathrm{KAl}\left(\mathrm{SO}_{4}\right)_{2}$, медный купорос $\mathrm{CuSO}_{4}$, железный купорос $\mathrm{FeSO}_{4}$, столовая сода.

Следует отметить, что не каждый яркоокрашенный гриб или растение можно использовать в крашении. Нахождение видов, отвечающих нашей цели, является кропотливой и сложной работой.

Сам процесс окраски несложен, но довольно долог и состоит из следующих этапов:

1. измельчение материала (на примере гриба Ganoderma lucidum) и добавление в него воды (рис. 3); 


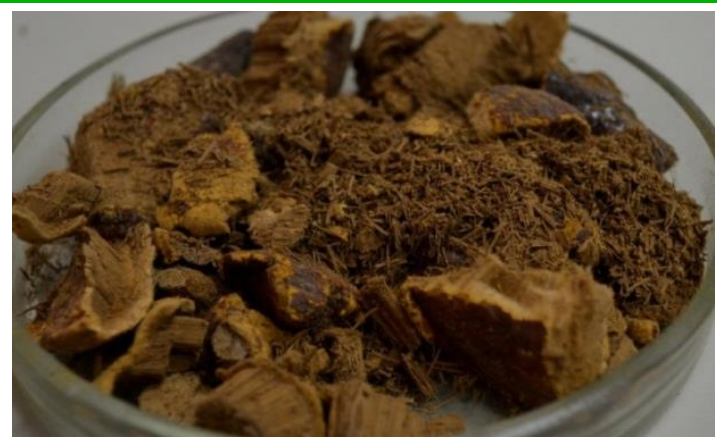

Puc. 3. Ganoderma lucidum

2. нагревание раствора на водяной бане до $80-90^{\circ} \mathrm{C}$ (около $1-1,5$ часа) (рис.4);

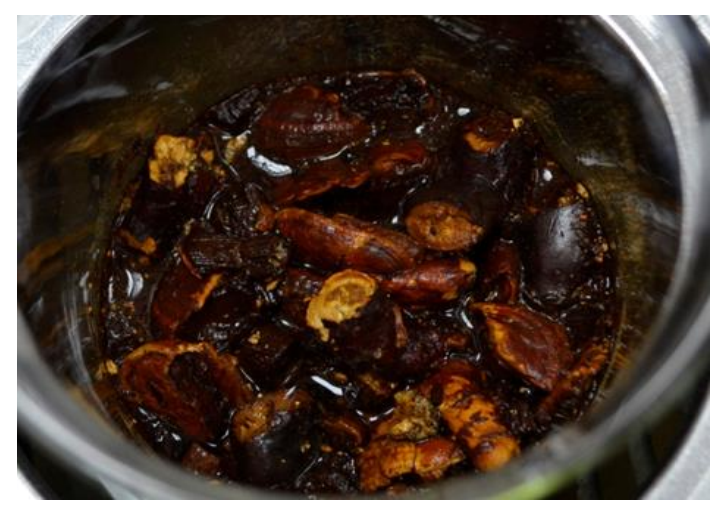

\section{Рис. 4. Раствор, приготовленный из Ganoderma lucidum}

3. фильтрование раствора, охлаждённого естественным путём до комнатной температуры (рис.5);

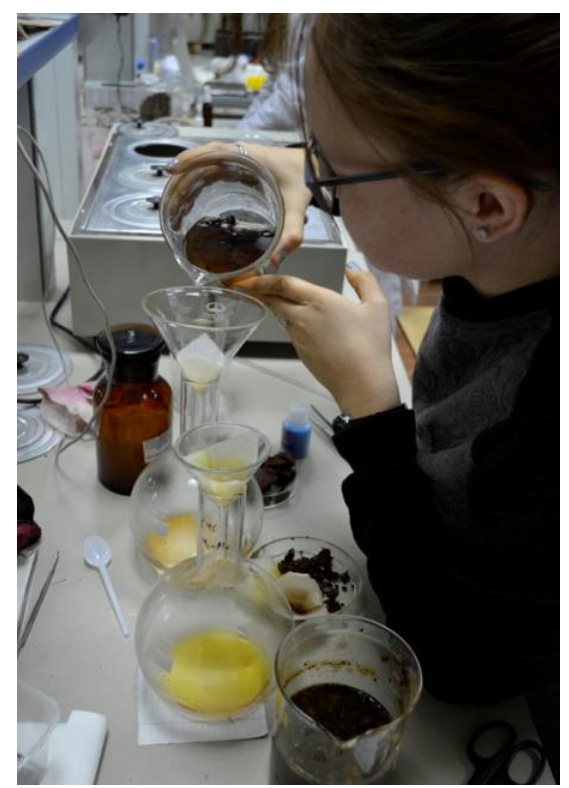

Рис. 5. Очистка раствора 
4. добавление в очищенный раствор протравленной шерсти (при температуре $80-90^{\circ} \mathrm{C}$, в период времени от 40 минут до 2 часов, периодически перемешивая) (рис. 6);

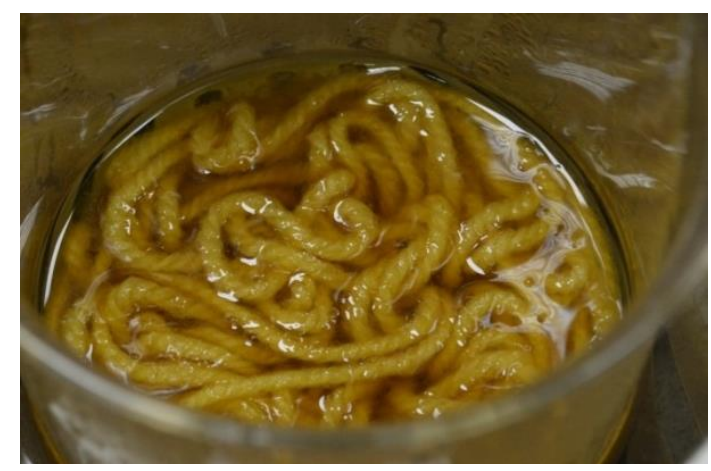

Рис. 6. Окрашивание шерсти

5. промывание окрашенной шерсти в мыльном растворе (рис. 7).

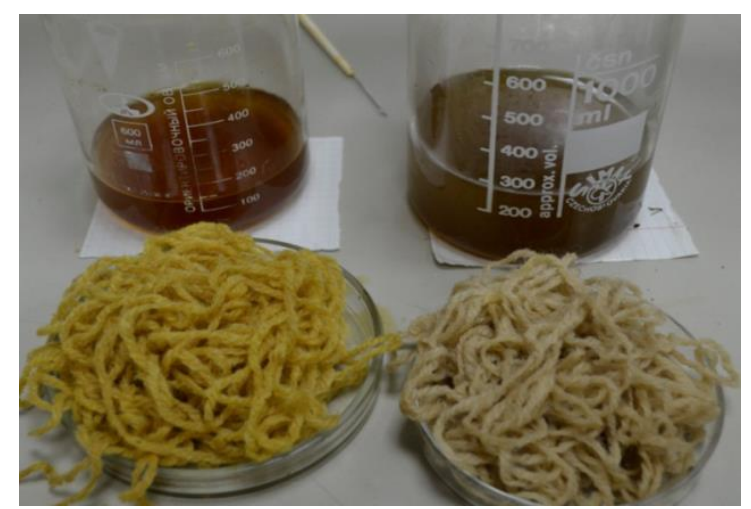

Рис. 7.Окрашенная шерсть грибами Phaeolus schweinitzii (слева) и Ganoderma lucidum (справа)

Некоторые результаты окраски шерсти грибами и растениями Волгоградской области представлены ниже.

\section{Cerioporus squamosus (Huds.) Quel - Tрутовик чешуйчатый}

50 г сушёных грибов, 100 г протравленной шерсти, реагент - $\mathrm{KAl}\left(\mathrm{SO}_{4}\right)_{2}$; получаемый цвет - бежевый.

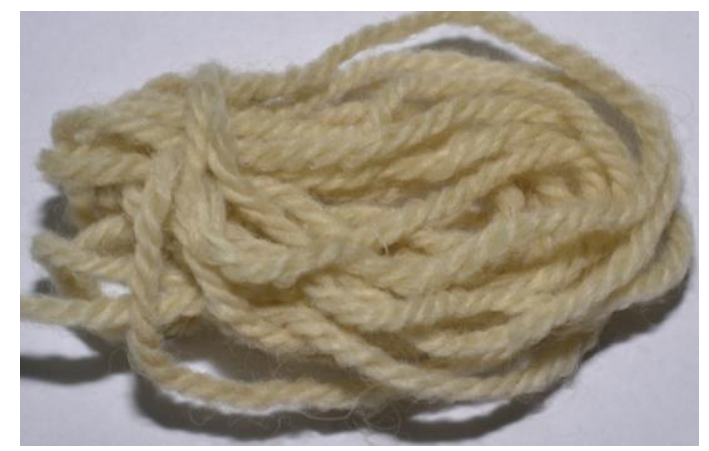

Pис. 8. Cerioporus squamosus 


\section{Ganoderma lucidum (Curtis) P. Karst. (Ганодерма лакированная)}

100 г сушёных грибов, 150 г протравленной шерсти, реагент $\mathrm{KAl}\left(\mathrm{SO}_{4}\right)_{2}$; получаемый цвет - коричневый.

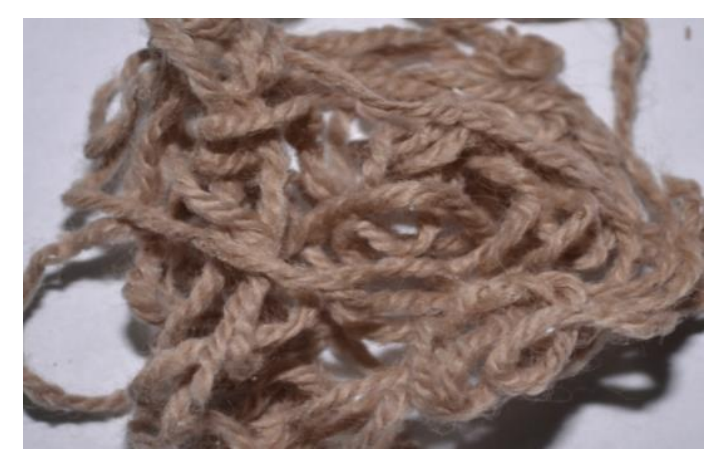

Pис. 9. Ganoderma lucidum

\section{Phaeolus schweinitzii (Fr.) (Трутовик Швейнища)}

50 г сушёных грибов, 100 г протравленной шерсти, реагент - $\mathrm{KAl}\left(\mathrm{SO}_{4}\right)_{2}$; получаемый цвет - жёлтый.

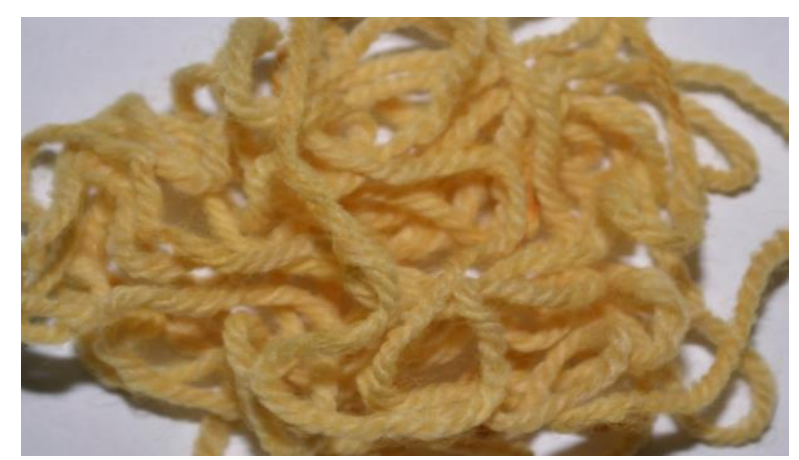

Pис. 10. Phaeolus schweinitzii

\section{Gloeophyllum sepiarium (Wulfen) P. Karst. (Трутовик заборный)}

50 г сушённых грибов, 50 г протравленной шерсти; получаемый цвет светло-коричневый.

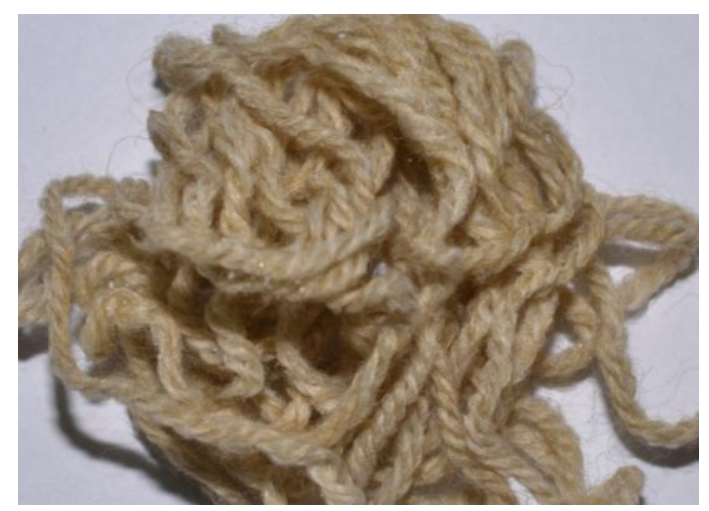

Рис. 11. Gloeophyllum sepiarium 


\section{Rubia tinctorum L. (Марена красильная)}

20 г сухого материала, 10 г протравленной шерсти; получаемый цвет при взаимодействие с $\mathrm{Na}_{2} \mathrm{SO}_{4}$ - светло бордовый цвет; без реагентов красноморковный цвет.

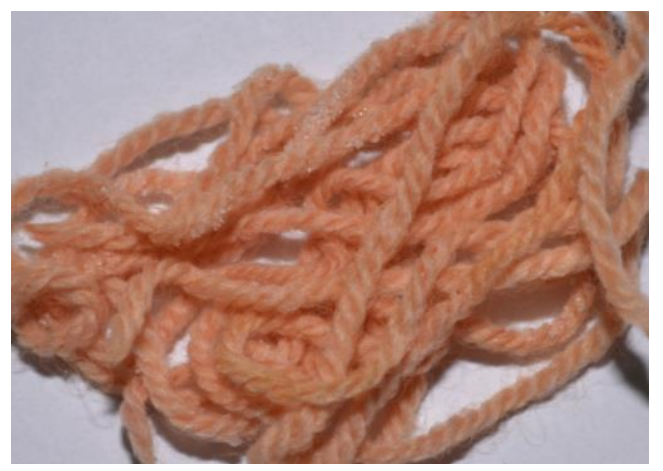

Рис. 11. Rubia tinctorum (без реагентов)

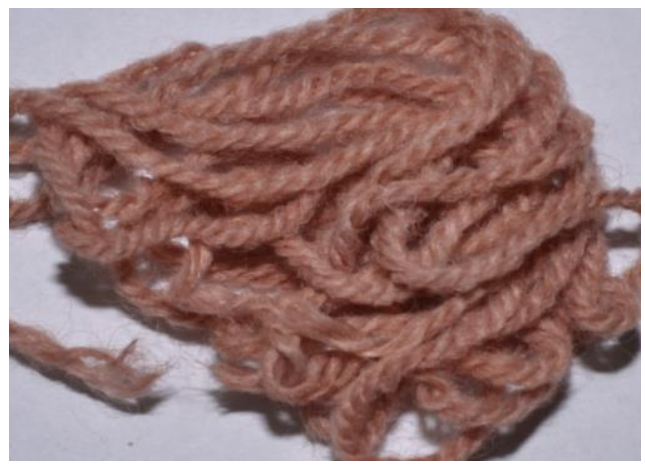

Pис. 12. Rubia tinctorum $\left(\mathrm{Na}_{2} \mathrm{SO}_{4}\right)$

Urtica dioica L. (Крапива двудомная)

25 г сухого материала, 10 г протравленной шерсти; получаемый цвет нежный светло-мятный цвет.

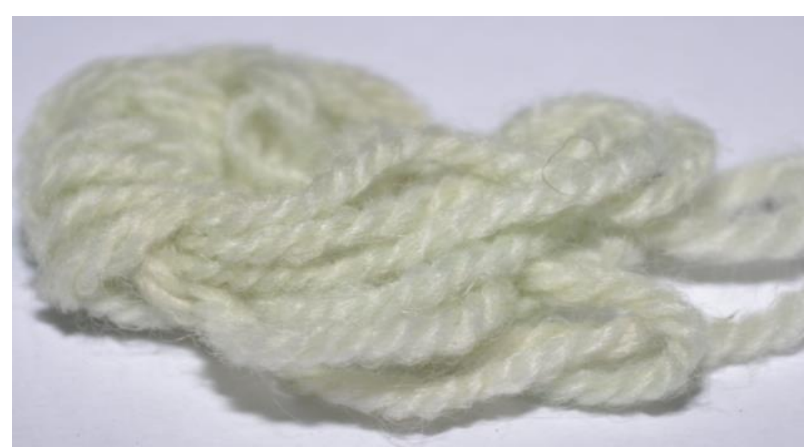

Pис. 13. Urtica dioica

\section{Matricaria recutita L. (Ромашка лекарственная)}

20 г сухого материала + 10 г протравленной шерсти; получаемый цвет светло жёлтый.

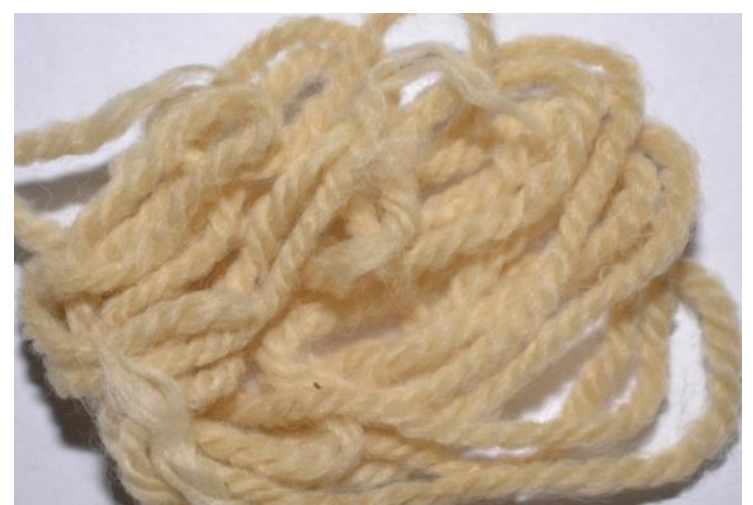

Puc. 14. Matricaria recutita

317 
В заключении стоит отметить, что использование нами подобранных техник окрашивания с опредёленным природным красителем позволяет получить стойкий цвет, и такие ткани могут быть использованы в современной эко-моде. Мы продолжаем наше исследование и пробуем новые материалы для опытов, чтобы цвет сохранялся дольше и был ярче.

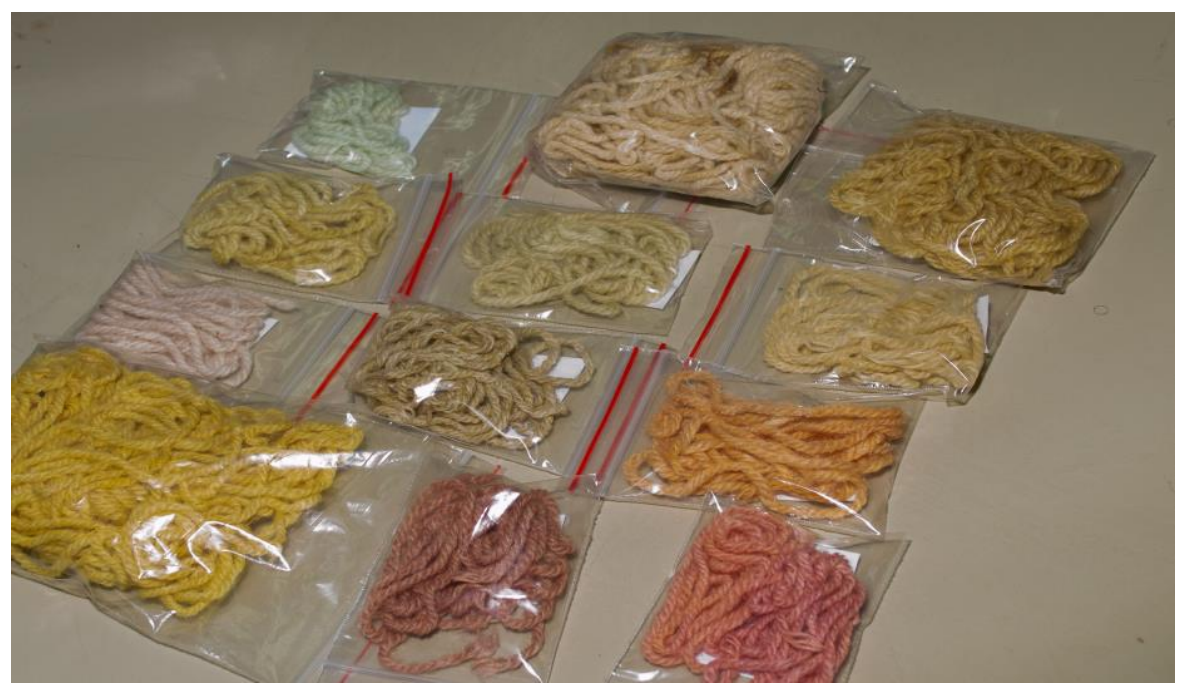

Рис. 15. Промежуточные результаты окрашивания

\section{Список литературы}

1. Агроклиматический справочник по Волгоградской области / А.П. Русеева [и др.].Ленинград: Гидрометеоиздат, 1967. 143 с.

2. Антонин В., Котлаба Ф., Клузак 3. Грибы. Большая энциклопедия Португалия: ЗАО «Издательский Дом Ридерз Дайджест», 2005.320 с.

3. Афонькин С.Ю. Большая иллюстрированная энциклопедия. Грибы России. Вильнюс: UAB «Bestiary», 2014. 224 с.

4. Брылёв В.А., Жбанов Ф.И., Самборский Ю.П. География Волгоградской области. Волгоград: Нижне-Волжское книжное издательство, 1989. 240c.

5. Бульонкова Т.М., Филлипова Н.В. Мастер-классы по крашению шерсти грибами на территории Югры // Биологические коллекции Югры: сбор, фиксация, хранение, введение в научный оборот: материалы научнометодического семинара в Музее Природы и Человека. 2017. С. 1-8.

6. Гагиева Н.Г. Технологический процесс крашения шерстяной пряжи в традиции коми (зырян) конца XIX - начала XX века // Исторические, философские, политические и юридические науки, культурология и искусствоведение. Вопросы теории и практики. 2012.№ 7 (21): в 3 ч. С. 25. 
7. Гарибова Л.В. Популярный атлас-определитель. Грибы. М.: Дрофа, 2009. $350 \mathrm{c}$.

8. Гарибова Л.В., Лекомцева С.Н. Основы микологии: морфология и систематика грибов и грибоподобных организмов. М.: Т-во научных изданий КМК, 2005. $220 \mathrm{c}$.

9. Дьяков Ю.Т., Шнырева А.В., Сергеев А.Ю. Введение в генетику грибов. М.: Академия, 2005. 304 с.

10. Королюк Е.А. Красильные растения Алтая и сопредельных территорий // Химия растительного сырья. 2003. №1. С. 101-135.

11. Рябинина Н.О. Сохранение эталонных степных экосистем и ландшафтов Волгоградской области // Вестн. Волгогр. гос. ун-та. Сер. 3, Экон. Экол. 2011. № 1 (18). С. 231-238.

12. Рябинина Н.О. История и перспективы развития сети особо охраняемых природных территорий в зоне степей юго-востока русской равнины // Известия АО РГО. 2017. № 2 (45). С. 61-70.

13. Сазонов В.Е. [и др.]. Доклад «О состоянии окружающей среды Волгоградской области в 2018 году». Ижевск: ООО «Принт», 2019. 300с. 